\title{
PRÁCTICAS DE GOBIERNO CORPORATIVO EN LAS ASAMBLEAS GENERALES DE ACCIONISTAS DE EMPRESAS LISTADAS EN COLOMBIA*
}

\author{
Gina-Paola González** \\ Alexander Guzmán *** \\ Francisco Prada ${ }^{* * *}$ \\ María-Andrea Trujillo ${ }^{* * * * *}$
}

doi:10.11144/Javeriana.cao27-49.pgca. Este artículo es producto de la investigación "Gobierno Corporativo" dirigida por el Colegio de Estudios Superiores de Administración CESA, Bogotá, Colombia desde diciembre de 2008. El artículo se recibió el 06/08/2014 y se aprobó el 01/12/2014. Sugerencia de citación: González, G.-P., Guzmán, A., Prada, F. y Trujillo, M.-A. (2014). Prácticas de gobierno corporativo en las Asambleas Generales de Accionistas de empresas listadas en Colombia. Cuadernos de Administración, 27 (49), 37-64. http://dx.doi.org/10.11144/Javeriana. cao27-49.pgca

** $\quad$ Magíster en Finanzas de la Universidad EAFIT, Medellín, Colombia, 2012. Tesorera de Prodiagnóstico S.A. de Medellín, Colombia. Correo electrónico: gpgonzalezf@gmail.com

*** Doctor en Administración de la Universidad de los Andes, Bogotá, Colombia, 2011. Profesor Titular de Investigación del Colegio de Estudios Superiores de Administración: CESA, Bogotá, Colombia. Correo electrónico: guzman. alexander@gmail.com

**** Especialista en Legislación Financiera de la Universidad de los Andes, Bogotá, Colombia, 2000. Corporate Governance Operations Officer, International Finance Corporation: IFC, Bogotá, Colombia. Correo electrónico: fjpradar@ gmail.com

***** Doctora en Administración de la Universidad de los Andes, Bogotá, Colombia, 2011. Profesora Titular del Colegio de Estudios Superiores de Administración: CESA, Bogotá, Colombia. Correo electrónico: matrujilda@gmail.com 


\section{Prácticas de gobierno corporativo en las} Asambleas generales de accionistas de empresas listadas en Colombia

\section{RESUMEN}

Este estudio analiza las Asambleas Generales de Accionistas (AGA) bajo el enfoque de gobierno corporativo, caracterizando las asambleas del año 2012 de once empresas colombianas que representan un poco más del $50 \%$ del COLCAP. Utilizando la metodología de Apostolides y los lineamientos del Código País, se construyen índices de evaluación respecto al deber ser de las asambleas. Se encuentra que en estas reuniones se desatienden aspectos fundamentales como el proceso de votación, la composición y remuneración de la junta, la revelación de información sobre los candidatos a la junta y la trasmisión de las AGA a través de internet. Por el contrario, se otorga mayor atención a los refrigerios, folletos, implementos de oficina y el lugar en el que se desarrolla la reunión.

Palabras clave: Gobierno corporativo, Asambleas Generales de Accionistas, accionista minoritario.

Clasificación JEL: G3, G38

\section{Corporate governance practices at Annual general meetings in listed firms in Colombia}

\section{Abstract}

This study analyzes the Annual General Meetings (AGM) under the corporate governance approach, taking in care the meetings for year 2012 of 11 Colombian firms which represent more than $50 \%$ of COLCAP. Referencing the Apostolides' AGM scorecard and the guidelines of the Country Code, are presented assessment indexes with respect to these meetings. The results show that in the AGM pay too little attention to some relevant aspects as the voting process, the composition and remuneration of the board members, the disclose information about the candidates for the board and the AGM transmission via the internet. On the other hand, it is given more importance to refreshments, stationery and office supplies, flyers and the location the AGM takes place.

Keywords: Corporate governance, Annual general meetings, minority shareholders.

JEL Classification: G3, G38

Práticas de governo
corporativo nas
Assembleias gerais de
acionistas de empresas
listadas na Colômbia

\section{RESUMO}

Este estudo analisa as Assembleias Gerais de Acionistas (AGA) sob o enfoque de governo corporativo, que caracteriza as assembleias de 2012 de 11 empresas colombianas que representam um pouco mais de $50 \%$ do COLCAP. Utilizando a metodologia de Apostolides e os lineamentos do Código do País, constroem-se índices de avaliação a respeito do dever ser das assembleias. Constata-se que, nessas reuniões, não se atendem a aspectos fundamentais como processo de votação, a composição e a remuneração do conselho diretivo, a revelação de informação sobre os candidatos ao conselho e a transmissão das AGA pela internet. Pelo contrário, outorga-se maior atenção aos lanches servidos, materiais de escritório, folhetos e ao lugar no qual se desenvolve a reunião.

Palavras-chave: Governo corporativo, Assembleias gerais de acionistas, acionista minoritário.

Classificação JEL: G3, G38 


\section{Introducción}

En la literatura económica el gobierno corporativo se ha estudiado principalmente bajo dos enfoques: el primero, sustentado en defender los intereses de los accionistas y que busca que las actividades de una compañía estén direccionadas de tal manera que el accionista asegure el retorno de la inversión (Jensen y Meckling, 1976; Shleifer y Vishny, 1997). Y el segundo enfoque bajo el cual el gobierno corporativo es concebido como un facilitador del bienestar de las partes interesadas de una empresa (proveedores, empleados, clientes, acreedores y accionistas) (Tirole, 2001). En los últimos años el segundo enfoque ha sido ampliamente adoptado y fue soportado por los Principios de Gobierno Corporativo promulgados por la Organización para la Cooperación y el Desarrollo Económico (OCDE) por primera vez en el año 2004, los cuales buscan que todos los agentes que participan en las actividades de gestión e inversión en una empresa se rijan bajo unos lineamientos o marco regulatorio en el que se definen sus derechos y deberes, y dentro del cual se gestiona la empresa (Superintendencia Financiera, 2010).

El diagnóstico realizado por Chong y López de Silanes (2007) sobre el estado del gobierno corporativo en los países latinoamericanos resalta cómo las empresas de esta región enfrentan un marco legal débil que trae como consecuencia un alto grado de concentración de la propiedad. Los estudios sobre gobierno corporativo que han utilizado para el análisis empresas de diferentes países latinoamericanos ratifican estos resultados (Chong y López de Silanes, 2007; Klapper y Love, 2004; Lefort, 2005). En general, estas economías tienen poco acceso al financiamiento externo para sus empresas y en consecuencia los costos de capital son altos. La Porta, López-de-Silanes, Shleifer y Vishny (1997) realizan un estudio en el que muestra que los países ven afectado su acceso a la financiación de acuerdo con la protección legal que ofrece a los accionistas.

El gobierno corporativo plantea a la empresa la posibilidad de complementar las deficiencias del marco legal del país a través del fortalecimiento de su marco legal interno en la búsqueda de una mayor protección a los inversionistas. Una empresa con buenas prácticas de gobierno señala transparencia y legalidad al mercado. En este contexto se desarrolla el presente artículo, evaluando la adopción de prácticas de buen gobierno en Colombia a nivel firma a través de la caracterización de las Asambleas Generales de Accionistas (AGA) en Colombia.

La AGA como máximo órgano social representa un espacio legítimo en donde se abordan y mitigan los conflictos de intereses entre accionistas mayoritarios y minoritarios, y entre los accionistas y los miembros de la junta que los representan. Strätling (2003) destaca tres funciones principales de las AGA: revelar información a los accionistas tanto financiera como estratégica, obtener el consentimiento de los accionistas en el proceso de toma de decisiones y generar debate entre accionistas y directivos.

Esta investigación se centra en caracterizar las AGA en Colombia, lo cual permite revisar cómo se desenvuelven estos espacios de de- 
liberación y gobierno y si las empresas están cumpliendo con los estándares que tanto la literatura como la regulación nacional e internacional han establecido para este órgano de gobierno en términos de buenas prácticas de gobierno corporativo.

Aun cuando se han presentado avances a nivel país y a nivel firma, luego de hacer una evaluación siguiendo los criterios de los trabajos de Apostolides $(2007,2010)$ y los lineamientos del Código País (Código de buen gobierno para empresas listadas), este estudio señala el nivel medio-bajo en el que se encuentra las AGA en Colombia como instrumentos de Gobierno Corporativo. Siguiendo los criterios de Apostolides, se encuentra que los procedimientos para ejercicio del voto no favorecen la participación del accionista minoritario, no se da suficiente importancia al espacio para preguntas por parte de los minoritarios a la alta dirección y la composición de la junta directiva y el informe de remuneración de la misma son desatendidos. Además, revisando el cumplimiento a las sugerencias presentadas por el Código País, se encuentra que no se permite el ejercicio del voto ni la asistencia a la reunión a través de medios electrónicos y no se presenta a los accionistas previamente al desarrollo de la AGA la información sobre el perfil de los candidatos a junta directiva.

Este artículo es relevante por varias razones: primero, las AGA cumplen un papel determinante en la mitigación de los conflictos de intereses entre accionistas, por lo que la reflexión respecto al funcionamiento de las mismas es necesaria para los actores del mercado de capitales. Segundo, en la literatura de gobierno corporativo los estudios han centrado el interés en el análisis de las juntas directivas y los análisis relacionados con las AGA como máximo órgano social son casi inexistentes para la región de América Latina e incipientes en el ámbito global. Tercero, las conclusiones que se presentan en referencia al caso colombiano son relevantes para los países emergentes en general por las similitudes en el marco institucional y en el desarrollo de los mercados de capitales. Finalmente, la reflexión respecto a las prácticas de gobierno corporativo es necesaria en un contexto de integración de los mercados de capitales. Por ejemplo, en el caso colombiano, a partir de mayo de 2011 se creó el Mercado Integrado Latinoamericano, MILA, un mercado de renta variable conformado por la Bolsa de Comercio de Santiago (Chile), la Bolsa de Valores de Lima (Perú) y la Bolsa de Valores de Colombia. Esta integración busca un mayor desarrollo del mercado de renta variable ofreciendo mayor diversificación al accionista y mayor cantidad de potenciales fuentes de financiación para las empresas.

Esta investigación está organizada como sigue. En el siguiente aparte se presenta el marco teórico relacionado con las AGA. En la segunda sección se realiza la descripción de la muestra y la metodología de evaluación a seguir. La tercera sección presenta la evaluación realizada y discute los resultados obtenidos. En la cuarta sección se proponen recomendaciones relacionadas con el "deber ser" de las AGA para orientar el trabajo de los actores de política pública. En la parte final se concluye. 


\section{Las AGA como órganos de gobierno corporativo}

Son escasos los estudios que abordan las Asambleas Generales de Accionistas (AGA) bajo el enfoque de gobierno corporativo desde una perspectiva financiera debido a que la mayoría de trabajos presentan un enfoque normativo (Zetzsche, 2005, 2007; Sjostrom, 2007; Fairfax, 2010). A continuación se presenta una revisión de literatura en la que se abordan diversos temas relacionados con las Asambleas Generales de Accionistas (AGA) bajo un enfoque de gobierno corporativo.

Los trabajos de Apostolides representan una secuencia que busca profundizar en el estudio de las AGA y su importancia en el gobierno de las empresas. El primero desarrollado en coautoría con Boden (Apostolides y Boden, 2005), representa un estudio etnográfico sobre las AGA que utiliza una muestra de empresas del Reino Unido y señala la pertinencia de las asambleas tanto para directivos como para accionistas, ya que los primeros evidencian su legitimidad en el cargo y los segundos se sienten parte de la empresa.

Apostolides (2007) toma una muestra de 22 AGA para empresas del Reino Unido, realizadas en el periodo 2001-2005 y conforma unos criterios que pueden ser agrupados en dos clases: aquellos considerados como los de mayor impacto sobre el modelo de gobierno corporativo y aquellos que afectan la satisfacción de los accionistas asistentes a la asamblea. El autor resalta como buenas prácticas de gobierno en las AGA una junta directiva abierta a los comentarios y obser- vaciones de los accionistas, la realización de las AGA en buenas instalaciones, buenos refrigerios, buen material disponible, un control balanceado de la reunión por parte de la alta dirección y mecanismos apropiados de ejercicio de voto; y como malas prácticas la poca disposición a escuchar a los accionistas y el mayor control por parte de los directivos.

Apostolides (2010) complementa el estudio anterior al analizar 44 AGA para una muestra de 33 empresas pertenecientes a cinco industrias del Reino Unido. Este estudio hace una evaluación más detallada de los criterios analizados y de la relación existente entre directivos y accionistas en las asambleas, resaltando características de una AGA exitosa, como una junta directiva bien balanceada, independiente y con esquemas de remuneración para los directores, conciencia de la importancia de la responsabilidad social corporativa y un reconocimiento real de los asuntos prioritarios para los accionistas.

Otro tema estudiado en la literatura consiste en los mecanismos de participación de los accionistas y el activismo de los mismos en las AGA. De Jong, Merten y Roosenboom (2006) estudian las votaciones que hacen los accionistas de las propuestas presentadas en un total de 245 asambleas generales de 54 empresas holandesas en el periodo 19982002. Las AGA de las empresas que conforman la muestra se caracterizan por el papel activo de los fondos de pensión privados y una estructura multinivel de las juntas directivas. Es decir, las empresas cuentan con dos tipos de juntas, una junta de administración encargada de la gestión de la empresa y otra de supervisión. Los autores resaltan la exis- 
tencia de diferentes tipos de acciones, lo que genera diferentes derechos de participación o voto. Los hallazgos encontrados por De Jong et al. (2006) señalan que las AGA son un foro que permite la rendición de cuentas de la administración de la empresa a los accionistas, pero en el que estos últimos tienen poca influencia en la gestión de la firma.

Poulsen, Strand y Thomsen (2010) analizan el poder de voto en el activismo de los accionistas en las AGA de Suecia. Para estos autores, en Suecia el grado de concentración de la propiedad es intermedia ya que los principales accionistas de las empresas que cotizan en bolsa poseen entre el $5 \%$ y el $50 \%$ de los derechos de voto, lo que facilita a los minoritarios ganar en las votaciones al formar coaliciones. Una de las particularidades de las AGA es la existencia del comité de nominación, el cual es una institución local de la que hacen parte los accionistas minoritarios. El Comité de nominación está conformado por accionistas privados individuales, es elegido en las reuniones anuales y se encarga de evaluar a la junta directiva y hacer propuestas a la asamblea. Los autores argumentan que la tasa de actividad de accionistas es muy baja comparada con países como Estados Unidos y Reino Unido y que si no fuera por el comité de nominación, los accionistas no llevarían propuestas a las AGA o lo harían en una proporción muy baja. Sin embargo, la existencia del comité de nominación hace a las empresas susceptibles a la influencia del accionista minoritario.

La importancia de las AGA como herramienta de un buen gobierno corporativo ha sido resaltada por diversos autores. Strätling
(2003) afirma que las AGA son un instrumento de gobierno corporativo que permite a los accionistas el acceso a los directores de una empresa, limitando así la posibilidad de expropiación de la riqueza de los accionistas por parte de los administradores y anota que las asambleas tienen tres funciones principales: primero, informar a los accionistas sobre el desempeño financiero de la empresa y las decisiones más importantes de la gestión; segundo, buscar que los accionistas den el consentimiento a la junta directiva para tomar decisiones que no están dentro de su discrecionalidad y; por último, proporcionar un foro que permita el debate entre directores $\mathrm{y}$ accionistas tanto de actuaciones pasadas como futuras.

El estudio de Strätling resalta que los accionistas consideran las AGA como un espacio que les permite mantener contacto visual con los directores, acceder a información de la empresa y representa una plataforma pública para el accionista. Además, aun cuando los accionistas prefieren asistir de manera presencial a las asambleas, al no poder asistir valoran la posibilidad de llevar a cabo su participación y ejercer su voto de manera virtual. En términos generales, este estudio resalta la importancia de las asambleas para los accionistas minoritarios.

Hodges, Macniven y Mellett (2004) estudian las AGA del sistema de servicios de salud pública del Reino Unido. El estudio se centra en revisar la asistencia del público a estas asambleas y la manera en que se desarrolla la reunión, en la cual no se somete a consideración la toma de decisiones, contrario a lo que sucede en las AGA de firmas privadas. 
Estas asambleas se centran en presentar la información financiera y facilitar el diálogo entre directivos y asistentes sobre temas que interesan a empleados de estas empresas quienes son los que más asisten a las Asambleas, ya que no hay toma de decisiones por parte de los accionistas. Por lo tanto, estas reuniones se asemejan a las audiencias de rendición pública de cuentas en el contexto colombiano y latinoamericano.

Iwatani y Taki (2009) muestran una evolución en las AGA en Japón debido al fortalecimiento en la regulación que promueve la seguridad, la disminución de empresas con participaciones cruzadas y de los escándalos corporativos, y la necesidad de tener quórum en el momento de tomar decisiones. El artículo destaca que las asambleas son importantes para tomar decisiones y que los fondos de pensiones están ejerciendo un papel activo en ellas. Lo anterior se evidencia en que los votos en contra de las propuestas que la dirección somete a votación en la asamblea han pasado del $17,5 \%$ en 1998 a $59,3 \%$ en 2007.

Finalmente, el flujo de información alrededor de las AGA representa la preocupación de la alta dirección por reducir las asimetrías de información entre la gerencia y los accionistas. Dimitrov y Jain (2011) demuestran que 40 días antes de que se lleve a cabo una AGA los rendimientos de las acciones son más altos que en el resto del año, y que las empresas buscan revelar buenas noticias antes de las asambleas para que éstas se desarrollen en un ambiente positivo. Además, los autores identifican tres factores que determina que los gerentes deseen informar buenas noticias: la presencia de inversionistas institucionales, la compensación económica de los directivos de la empresa, y el activismo de los accionistas.

Los trabajos aquí reseñados señalan la importancia de las AGA en el contexto del gobierno corporativo, como un escenario válido para el ejercicio de los derechos de los accionistas minoritarios que puede ser aprovechado dependiendo de su activismo. Además, se evidencia que algunas empresas facilitan la participación de los accionistas minoritarios, mientras que otras la evitan.

\section{Descripción de la muestra y metodología}

El estudio de las AGA como máximo órgano social ha tomado importancia dentro de las agendas de investigación en gobierno corporativo. El trabajo de Apostolides y Boden (2005) y los de Apostolides (2007, 2010) han contribuido tanto al entendimiento de la dinámica de este tipo de espacios de deliberación y gobierno en el contexto de buenas prácticas de gobierno corporativo, como al análisis de la importancia de la realización de los mismos como escenario legítimo de rendición de cuentas y protección de los derechos de los accionistas. El cuestionamiento planteado por Strätling (2003) relacionado con la baja asistencia a las asambleas realizadas en el Reino Unido y los altos costos que las empresas asumen para preparar dichos espacios representa el punto de partida del trabajo de Apostolides y Boden (2005). Estos autores realizaron un estudio etnográfico sobre diez asambleas - una por cada empresa- del Reino Unido entre los años 2001 y 2002; y tomaron de éstas elementos comunes 
y las agruparon para analizar aspectos tales como la dinámica existente entre la junta directiva y los accionistas, el contenido de los temas que se trataron, el lugar en donde se realizó el evento y el contexto de la empresa en ese momento. Este trabajo señaló que, en general, en las asambleas analizadas no se alcanza una solución a los conflictos existentes entre accionistas minoritarios y la junta directiva, la alta dirección toma esos espacios como escenarios para reafirmar una posición dominante y los accionistas minoritarios acuden solo con el interés de sentirse parte de la empresa.

La investigación realizada en 2005 se complementó con los trabajos de Apostolides de 2007 y 2010, en los cuales se definieron doce categorías para medir el desempeño de las asambleas de accionistas usando un sistema de evaluación el cual se usará en el presente artículo para evaluar la muestra. Adicionalmente, se utiliza un sistema de evaluación propio y se aplica a los resultados de la encuesta Código País (Código de buen gobierno para empresas listadas en Colombia) dentro del periodo de estudio 2008 al 2011 para las empresas de la muestra.

\subsection{La muestra}

La muestra comprende las asambleas generales de accionistas para once empresas listadas en el mercado de capitales en Colombia (ver cuadro 1). Esta muestra representa el 13,23\% del total de empresas que hacen parte de la Bolsa de Valores de Colombia, BVC; sin embargo, el cuadro 1 señala que las mismas representan aproximadamente el 50\% del índice COLCAP, índice confor- mado por las 20 acciones más líquidas y relevantes del mercado colombiano y que define la participación de las empresas por su capitalización en el mercado. Además representan aproximadamente el $29 \%$ de la canasta del Índice General de la Bolsa de Valores de Colombia, IGBC, que tiene en cuenta las acciones líquidas y pondera su participación en la canasta según los volúmenes transados. De estas empresas, ocho están ubicadas entre los 30 primeros puestos de capitalización bursátil de la BVC, y tan sólo dos están por debajo del puesto 50 (Edatel en el puesto 56 y Enka de Colombia en el puesto 69). Estas empresas se caracterizan por alta concentración en la propiedad y por la participación de los fondos de pensiones en su composición accionaria.

De las empresas que conforman la muestra, siete están afiliadas al grupo económico más grande del país: el Grupo Empresarial Antioqueño, GEA ${ }^{1}$; el Grupo Bancolombia, el banco más grande del país; Celsia, una empresa de servicios públicos dedicada a la generación y distribución de energía eléctrica; Grupo Nutresa, líder en la fabricación y comercialización de alimentos; Protección, empresa administradora de fondos de pensiones y cesantías; Grupo de Inversiones Suramericana, compañía holding en los sec-

El GEA es un conglomerado de empresas en diferentes industrias en los sectores de cemento, alimentos, metalurgia, tabaco, construcción, textil, financiero, banca de inversión y seguros. El grupo lo conforman más de cien compañías caracterizadas por estructuras de propiedad cruzada. Su nombre proviene de la provincia en la cual sus compañías líderes tienen sus operaciones principales, Antioquia, uno de los departamentos más importantes del país. 
Cuadro 1. Empresas de la muestra, 2012

\begin{tabular}{|c|c|c|c|c|}
\hline Empresa & $\begin{array}{l}\text { Capitalización bursátil } \\
\text { (millones COP) }\end{array}$ & $\begin{array}{l}\text { COLCAP } \\
(\%)\end{array}$ & $\begin{array}{c}\text { IGBC } \\
(\%)\end{array}$ & Sector \\
\hline Grupo Bancolombia S.A. & 23.739 .578 & 13,66 & 12,82 & Financiero \\
\hline $\begin{array}{l}\text { Grupo de Inversiones } \\
\text { Suramericana S.A. }\end{array}$ & 18.007.928 & 12,52 & 5,32 & Financiero \\
\hline $\begin{array}{l}\text { Interconexión Eléctrica S.A. } \\
\text { E.S.P. (ISA) }\end{array}$ & 13.048 .446 & 6,43 & 1,33 & $\begin{array}{l}\text { Servicios } \\
\text { Públicos }\end{array}$ \\
\hline Almacenes Éxito S.A. & 13.788.752 & 7,50 & 4,43 & Comercial \\
\hline Grupo Nutresa S.A & 9.588 .973 & 6,90 & 2,13 & Industrial \\
\hline Isagen S.A. E.S.P. & 6.787 .919 & 2,89 & 1,97 & $\begin{array}{l}\text { Servicios } \\
\text { Públicos }\end{array}$ \\
\hline Colinversiones (CELSIA) & 3.216 .543 & & 0,55 & $\begin{array}{l}\text { Servicios } \\
\text { Públicos }\end{array}$ \\
\hline Mineros S.A. & 1.046 .750 & & 0,12 & Minería \\
\hline Protección S.A. & 1.187 .957 & & & Financiero \\
\hline Edatel S.A. E.S.P. & 283.633 & & & $\begin{array}{l}\text { Servicios } \\
\text { Públicos }\end{array}$ \\
\hline Enka de Colombia S.A. & 88.656 & & 0,09 & Industrial \\
\hline Totales & 90.785 .133 & 49,90 & 28,76 & \\
\hline
\end{tabular}

Fuente: página web de la Bolsa de Valores de Colombia, fecha de captura 21-07-2012.

Notas: El COLCAP es un indicador que refleja las variaciones de los precios de las 20 acciones más líquidas de la Bolsa de Valores de Colombia (BVC), donde el valor de Capitalización Bursátil ajustada de cada compañía determina su participación dentro del índice. El índice de la Bolsa de Valores de Colombia es el IGBC, el cual corresponde al indicador bursátil del mercado de acciones y refleja el comportamiento promedio de los precios de las acciones en el mercado. Para ser contempladas en la canasta del IGBC, las acciones deben tener una rotación en el semestre anterior mayor o igual al 0,5\% y una frecuencia de negociación en el trimestre inmediatamente anterior sea superior o igual al 40\%. La participación de cada acción en el IGBC depende de la ponderación de los volúmenes transados.

tores de banca, seguros, pensiones, ahorro e inversión; Grupo Éxito, líder en el comercio al detal en el país; y Enka, empresa dedicada a la producción y comercialización de polímeros y fibras químicas. Las empresas restantes son Interconexión Eléctrica S.A., ISA, holding estatal en los sectores de transporte de energía eléctrica y telecomunicaciones; Isagen, empresa estatal con accionistas privados dedicada a la generación y comerciali- zación de energía; Grupo Mineros, dedicado a la exploración y explotación de metales preciosos especialmente oro; y Edatel, empresa estatal con accionistas privados en el sector de telecomunicaciones.

La información obtenida para cada una de las asambleas es el resultado de la asistencia a las mismas por parte de los autores. De las once asambleas que conforman la muestra, 
tres se realizaron y se presenciaron a través de internet (Isa, Isagen y Grupo Nutresa). La metodología de estudio etnográfico ha sido previamente utilizada para el análisis de las AGA. De acuerdo con Apostolides y Boden (2005), la participación en las asambleas permite observar si en estas reuniones se generan oportunidades para el involucramiento de los diferentes accionistas en las decisiones y gobierno de la empresa. Sin embargo, así como lo reconocen Apostolides y Boden, estas observaciones pueden no ser concluyentes y no contar con los niveles de objetividad esperados. Sin embargo, consideramos que se ha realizado un análisis robusto y riguroso en este estudio. Las AGA objeto de la muestra se llevaron a cabo durante el primer trimestre del año 2012 y para complementar el análisis se revisaron las respuestas a la encuesta relacionada con el cumplimiento del Código País para cada una de estas empresas para el periodo 2008-2011. No fue posible revisar otro tipo de documentos debido a restricciones para acceder a los mismos.

Los autores reconocemos las limitaciones de la muestra. Aun cuando es una muestra representativa en cuanto al valor del mercado es muy reducida en el número de casos. Sin embargo, en defensa de este trabajo es necesario mencionar que el número de las empresas listadas en Colombia para el año en estudio, de acuerdo con información del Banco Mundial, es tan solo de 76, lo que implica que la muestra representa el 14\% del total de empresas listadas en el mercado. Además, de los emisores de alta bursatilidad para el año 2012 nuestra muestra cubre el $35 \%$. Por lo anterior sabemos que la muestra es representativa respecto a lo que sucede en las empresas más relevantes en el mercado de capitales, un mercado cada vez más importante en el contexto latinoamericano. Para el año 2001 la capitalización bursátil del mercado colombiano representaba tan solo el 13,5\% del Producto Nacional Bruto, mientras que en el año 2012 ya representaba el 70,9\%, ocupando el segundo lugar en este ratio en la región, superado únicamente por Chile de acuerdo con el Banco Mundial.

Lo anterior no implica que estemos exentos de sesgos en la investigación. Es necesario aclarar que algunas empresas no estuvieron dispuestas a recibir al grupo de investigación para adelantar el estudio. Así que los resultados podrían estar direccionados por las empresas con mayor disposición a compartir su información con actores externos. Sin embargo, aun así los resultados muestran un desempeño medio-bajo de las empresas en relación con las prácticas de buen gobierno en sus asambleas. Seguramente una muestra más amplia ratificaría y haría más críticos nuestros hallazgos.

\subsection{Metodología}

Apostolides (2007) desarrolla un sistema de evaluación para construir un índice que se obtiene de la calificación de doce criterios con valores de $0,-1$ y 1 . El objetivo es evaluar si en las asambleas se percibe un trato preferencial hacia al accionista minoritario en una escala que otorga un valor de cero en el caso en que no fuera posible observar un favorecimiento a los directores o a los accionistas minoritarios, un valor de 1 cuando se le da prioridad al accionista minoritario 
en la asamblea, y un valor de -1 cuando los directivos priorizan sus intereses.

Los criterios considerados por Apostolides $(2007,2010)$ se pueden clasificar en dos grupos. Aquellos fundamentales relacionados con el gobierno corporativo de las empresas (agenda, balance of board, remuneration report, address, voting procedure, control and questions) y otros que influencian la satisfacción del accionista en la AGA y que pueden afectar su buen desarrollo (venue, refreshments, materials, security and proxies). El panel A del cuadro 2 muestra los criterios definidos por Apostolides (2007). Utilizando estos criterios, en una primera etapa se evalúan las AGA que componen la muestra en el contexto de gobierno corporativo.

Posteriormente se realiza una evaluación de las mismas AGA teniendo en cuenta el Código País, el cual representa una compilación de recomendaciones de mejores prácticas de Gobierno Corporativo para emisores del sector real y financiero. Este documento fue elaborado por la iniciativa de la Superintendencia Financiera, la Superintendencia de Sociedades, la Bolsa de Valores de Colombia, y Confecámaras, entre otros. El Código reúne 41 medidas o recomendaciones que las empresas listadas en el mercado de valores en Colombia deben seguir para contar con un buen gobierno corporativo. Estas medidas están agrupadas en cuatro categorías relacionadas con la asamblea de accionistas, juntas directivas, información financiera y no financiera y solución de controversias. Para cumplir con el alcance del estudio, la categoría de interés es la correspondiente a las AGA.
Del Código País surge una encuesta llamada Encuesta Código País, la cual se aplica anualmente a las empresas listadas (establecida por la Circular Externa 028 de 2007 de la Superintendencia Financiera, mediante la cual se adopta la obligación de diligenciar y remitir la encuesta sobre la adopción de las recomendaciones del Código de Mejores Prácticas Corporativas de Colombia). La primera se realizó en el año 2007 bajo el principio de cumpla o explique, es decir, las empresas dan respuesta a 80 preguntas de donde se puede inferir si adoptan o no las recomendaciones en el Código País. Cuando deciden no adoptarlas, deben explicar por qué no lo hacen.

De las 80 preguntas que conforman la Encuesta Código País, se revisaron las 20 que están relacionadas con las AGA para cada una de las empresas que componen la muestra en los años 2008, 2009, 2010 y 2011. De las 20 preguntas, cinco están relacionadas con la convocatoria de la AGA, siete con la celebración de la reunión, una con la aprobación de operaciones relevantes, y siete con los derechos y trato equitativo de los accionistas (ver panel B del cuadro 2).

Las empresas que en cada pregunta respondieron sí reciben una calificación de 1 en esa pregunta en particular, las que respondieron no reciben una calificación de - 1 y las respuestas n.a. (no aplica) reciben una calificación de 0 . Lo anterior permite analizar el desempeño de cada una de las empresas en este aspecto y realizar un análisis comparativo con la evaluación realizada siguiendo la metodología planteada por Apostolides (2007, 2010). 


\section{Cuadro 2. Criterios de evaluación}

\section{Panel A: Criterios de Apostolides (2007) para evaluar AGA}

La agenda

¿Cómo está estructurada formalmente la reunión? En particular, ¿se presentan intentos para usar el orden de la reunión o los sistemas de votación para influenciar los resultados? Por ejemplo, la resolución para aceptar los estados financieros normalmente se ubica primero en el orden del día como un asunto general sobre el que los asistentes no pueden preguntar prácticamente nada.

La sede

El montaje, la música de fondo y el ambiente de la asamblea general de accionistas pueden influenciar la naturaleza de la reunión, y estos aspectos en están en las manos de los miembros de junta directiva desde el principio. Un lugar lujoso puede ser un obsequio o consentimiento que disfrutan los pequeños accionistas, o puede ser igualmente evidencia de que los miembros de junta directiva tratan de impresionar a los accionistas y atemorizarlos para que estén silenciosos. La ubicación geográfica también es un factor, en la medida en que el acceso para los accionistas varía según donde estén radicados.

\section{El refrigerio}

Es común el ofrecer bebidas antes de la reunión y un refrigerio o algo de comer después de la misma. Los accionistas minoritarios dan gran importancia a la comida y bebidas ofrecidas, y ocasionalmente presentan cuestionamientos respecto a su calidad. La ausencia de refrigerio puede ser utilizada para acortar el tiempo de la reunión y evitar la interacción entre los accionistas.

Los materiales

Artículos informativos y de apoyo respecto a la reunión, preguntas previas a la reunión contestadas de manera rápida y acertada, paquetes de información financiera extras para ser entregados en la reunión y otros materiales, son señales de que todos los aspectos de la reunión han sido considerados preparados de manera detallada por los funcionarios de la empresa y que la reunión tiene mayor probabilidad de ser transparente y abierta. Tal conducta

recibirá una calificación de "1". Ocasionalmente los accionistas reciben regalos como bolígrafos, postales, maletas, chocolates, botellas de vino, etc. Estos pueden, dependiendo del contexto, actuar como "endulzantes" para mantener a los accionistas contestos, pero también pueden demostrar un intento genuino por conseguir valiosos partidarios o simpatizantes.

\section{La seguridad}

Aunque la seguridad y prevención son obviamente valiosas, un enfoque agresivo u opresivo puede evidenciar intentos de intimidar o silenciar miembros. Seguridad excesiva, al estilo de aeropuertos, caminando a través de magnetómetros, revisión de maletas y personal de seguridad corpulento puede evidenciar que la empresa está esperando alteraciones y posibles protestas.

La composición de la Junta Directiva

Si las empresas dicen promover igualdad y diversidad en sus políticas entonces es razonable comprobar su compromiso verificando esas cualidades en la composición de su junta directiva y sus empleados. Dicho esto, la mayoría de juntas directivas están conformadas por hombres de edad media y avanzada. En contraste, algunas juntas muestran mayor diversidad. Evidencia de esa diversidad da mejor puntuación bajo este esquema.

Informe de la dirección

La presentación formal que realiza el presidente de la junta y los demás miembros en una asamblea general de accionistas es una oportunidad obvia de rendición de cuentas. Hacer una presentación exagerada sobre resultados modestos, culpar a todos excepto a la junta cuando las cosas salen mal o dejar de lado aspectos negativos de desempeño sin confrontarlos apropiadamente castiga la calificación de este aspecto. Una presentación abierta y realista lleva a una buena calificación. 
Retribución económica de la Junta Directiva

El reporte de voto de accionistas sobre la remuneración de los miembros de junta directiva en las asambleas generales de accionistas desde el año 2003 ha tenido un impacto significativo sobre la importancia de las asambleas generales de accionistas y su cobertura en medios y ha alentado la discusión sobre un asunto que descansa en el corazón de la relación principal-agente. Cuando se presentan asuntos obvios de inequidad sin intervención de la junta para corregir el exceso o modificar los contratos aún dado el desacuerdo de los accionistas, la puntuación será negativa. Acciones tempranas al desacuerdo de los accionistas obtienen puntuación de "1" como indicador de compromiso con las preocupaciones de los accionistas.

Control

El control sobre la reunión ejercido por la junta refleja el balance de poder y la naturaleza del intercambio. Un excesivo manejo de la alta gerencia obtiene "-1". La libertad de los participantes para expresar sus puntos, incluso cuando en ocasiones son triviales o repetitivos, y la manera en que éstos son recibidos - quizás cortésmente o con humor - merece un "1", así como un ambiente más casual para pasar el micrófono a aquellos sentados (siendo por lo tanto menos intimidante para aquellos más inexpertos).

El procedimiento de votación

¿El método de voto y revelación de resultados es utilizado para evitar debate o discusión? Los medios más seguros para los miembros de junta son las encuestas por votación, en la medida en que un número de decisiones casi invariable serán tomadas a favor de la junta por la mayoría de votos por poder en su dominio. Esto, o el procedimiento de voto a mano alzada realizado en los primeros cinco minutos de la reunión (buscando evitar discusión controversial) obtendrá "-1". La votación a mano alzada es riesgosa, en la medida en que algunos miembros con una participación menor en la empresa pueden registrar una mayoría en contra de la junta directiva. Este método merece "1". La ubicación de dispositivos en cada silla para que los votantes registren sus preferencias en el tiempo establecido mientras que se muestran los resultados en una pantalla de manera casi inmediata también merece "1".

Las preguntas

¿El procedimiento utilizado para las preguntas genera una atmósfera transparente y abierta o es estrictamente controlado y restringido? Registrar las preguntas con antelación y hacer filas en puntos específicos para usar el

micrófono puede desalentar la espontaneidad y le permite a la junta ganar poder y la habilidad para seleccionar las preguntas que prefiere. Una invitación honesta a que los accionistas expresen sus inquietudes merece un "1".

Poderes de votación

Ocasionalmente, aunque de manera muy poco frecuente, aquellos que atienden la asamblea en representación de algún accionista cuentan con la oportunidad de hablar. La legislación eventualmente puede permitir esto. La revelación de los votos por poder o delegados al momento de la reunión, en lugar de hacerlo de manera posterior muestra que las empresas ofrecen y proveen información y se califica con "1", aunque esto se está convirtiendo en una práctica común. Un menor nivel de explicación y oportunidad otorgado a los representantes o delegados se califica de manera negativa.

Fuente: Panel A traducido y adaptado de Apostolides (2007).

\section{Panel B: Preguntas relacionadas con AGA incluidas en la Encuesta Anual del Código País. El Código País representa en Código de mejores prácticas corporativas en Colombia}

I. Asambleas Generales de Accionistas

Convocatoria

P 1 En la última Asamblea General de Accionistas, ¿fue puesta a disposición de aquellos, dentro del término de la convocatoria y en el domicilio social, la documentación necesaria para su debida información sobre los temas a tratar? 


\begin{tabular}{|c|c|}
\hline P 2 & $\begin{array}{l}\text { La información puesta a disposición de los accionistas, durante el término de la Convocatoria a la Asamblea } \\
\text { General de Accionistas ¿contiene la propuesta de candidatos a integrar la Junta Directiva? }\end{array}$ \\
\hline P 3 & $\begin{array}{l}\text { ¿El emisor tuvo a disposición de los accionistas la información financiera sobre las sociedades subordina- } \\
\text { das y la matriz del emisor? (En caso de que el emisor tenga vinculación con una matriz y/o subordinadas, } \\
\text { responda la pregunta, en caso contrario, responda N/A). }\end{array}$ \\
\hline P 4 & $\begin{array}{l}\text { ¿La convocatoria de la última Asamblea General de Accionistas y de cualquier otra información necesaria } \\
\text { para el desarrollo de la misma, fue difundida en la página Web del emisor? }\end{array}$ \\
\hline P 5 & $\begin{array}{l}\text { ¿Se desagregaron los diferentes asuntos por tratar en el orden del día establecido para las Asambleas } \\
\text { de Accionistas llevada a cabo durante el período evaluado? }\end{array}$ \\
\hline \multicolumn{2}{|c|}{ Celebración } \\
\hline P 6 & $\begin{array}{l}\text { La segregación fue aprobada por la Asamblea General de Accionistas? (en el caso de haberse adelanta- } \\
\text { do una segregación en los términos del glosario responda la pregunta, en caso contrario responda N/A. } \\
\text { La segregación es una operación mediante la cual una sociedad, que se denomina "segregante" destina } \\
\text { una o varias partes de su patrimonio a la constitución de una o varias sociedades o al aumento de capital } \\
\text { de sociedades ya existentes, que se denominarán "beneficiarias". Como contraprestación, la sociedad } \\
\text { segregante recibe acciones, cuotas o partes de interés en las sociedades beneficiarias.) }\end{array}$ \\
\hline P 7 & $\begin{array}{l}\text { ¿La segregación fue incluida en la Convocatoria de la Asamblea donde fue adoptada? (en el caso de ha- } \\
\text { berse adelantado una segregación en los términos del glosario responda la pregunta, en caso contrario } \\
\text { responda N/A) }\end{array}$ \\
\hline P 8 & $\begin{array}{l}\text { ¿El cambio de objeto social fue incluido en la Convocatoria de la Asamblea donde fue adoptada? (en el caso } \\
\text { de haberse modificado el objeto social del emisor responda la pregunta, en caso contrario responda N/A). }\end{array}$ \\
\hline P 9 & $\begin{array}{l}\text { ¿Fue incluida la renuncia al derecho de preferencia en la suscripción en la Convocatoria de la Asamblea } \\
\text { donde fue adoptada? (en el caso de haberse adoptado en la asamblea de accionistas la renuncia al dere- } \\
\text { cho de preferencia en la suscripción, responda la pregunta, en caso contrario responda N/A. El derecho } \\
\text { de preferencia en la suscripción es el derecho según el cual los accionistas podrán suscribir preferen- } \\
\text { cialmente en toda nueva emisión de acciones una cantidad proporcional a las que posean en la fecha en } \\
\text { que se apruebe el Reglamento, en el cual se indicará el plazo para suscribir, que no podra ser inferior a } \\
\text { quince días contados desde la fecha de la oferta). }\end{array}$ \\
\hline P 10 & $\begin{array}{l}\text { ¿El cambio del domicilio social, fue incluido en la Convocatoria de la Asamblea dónde fue adoptada? (en } \\
\text { el caso en que la Asamblea de Accionistas haya modificado el domicilio social, responda la pregunta, en } \\
\text { caso contrario responda N/A). }\end{array}$ \\
\hline P 11 & $\begin{array}{l}\text { ¿Fue incluida la disolución anticipada en la Convocatoria de la Asamblea donde fue adoptada? (en el caso } \\
\text { en que la Asamblea de Accionistas haya adoptado la disolución anticipada, responda la pregunta, en caso } \\
\text { contrario responda N/A. La disolución anticipada representa la posibilidad que tienen los asociados de } \\
\text { llevar a cabo, por causas diferentes a las legalmente establecidas, el trámite encaminado a la liquidación } \\
\text { de la sociedad, para lo cual deberá pagarse el pasivo externo y luego distribuir el remanente). }\end{array}$ \\
\hline P 12 & $\begin{array}{l}\text { ¿El emisor cuenta con mecanismos electrónicos que permitan a los accionistas que no pueden asistir a } \\
\text { la Asamblea de Accionistas, accedan a información sobre su desarrollo? }\end{array}$ \\
\hline \multicolumn{2}{|c|}{ Aprobación de operaciones relevantes } \\
\hline P 13 & $\begin{array}{l}\text { ¿Las operaciones relevantes realizadas con vinculados económicos a precios diferentes a los de mer- } \\
\text { cado o que no hacen parte del objeto social fueron aprobadas por la Asamblea General de Accionistas? }\end{array}$ \\
\hline
\end{tabular}




\begin{tabular}{|l|l|}
\hline \multicolumn{2}{|l|}{ Derecho y trato equitativo de los accionistas } \\
\hline P 14 & $\begin{array}{l}\text { ¿El emisor da a conocer al público con claridad, exactitud e integridad, los derechos y obligaciones inhe- } \\
\text { rentes a la calidad de accionistas? }\end{array}$ \\
\hline P 15 & ¿El emisor pone en conocimiento del público de manera permanente las clases de acciones emitidas? \\
\hline P 16 & ¿El emisor pone en conocimiento del público de manera permanente la cantidad de acciones emitidas? \\
\hline P 17 & $\begin{array}{l}\text { ¿El emisor pone en conocimiento del público de manera permanente la cantidad de acciones en reserva } \\
\text { para cada clase de acciones? }\end{array}$ \\
\hline P 18 & ¿El emisor cuenta con un reglamento interno de funcionamiento de la asamblea general de accionistas? \\
\hline P 19 & $\begin{array}{l}\text { ¿El Reglamento Interno de Funcionamiento de la Asamblea General de Accionistas incluye medidas } \\
\text { sobre su Convocatoria? }\end{array}$ \\
\hline P 20 & $\begin{array}{l}\text { ¿El Reglamento Interno de Funcionamiento de la Asamblea General de Accionistas incluye medidas } \\
\text { sobre su Celebración? }\end{array}$ \\
\hline
\end{tabular}

Fuente: Superintendencia Financiera de Colombia (SFIN).

\section{Análisis de resultados}

\subsection{Evaluación de las $A G A$ utilizando la metodología de Apostolides}

El cuadro 3 muestra los resultados obtenidos del análisis individual por compañía con base en la evaluación individual realizada por los autores siguiendo Apostolides (2007). El panel A del cuadro 3 muestra el ranking de desempeño de las AGA bajo estos criterios. La empresa que en promedio cumple con mejores estándares de buen gobierno corporativo en su AGA es Mineros S.A. con un índice de 10 sobre 12 criterios, para un $83,33 \%$ de calificación porcentual. Esta empresa tiene como principal accionista al Grupo Colpatria y se dedica a la explotación de metales preciosos, específicamente el oro. Sus resultados financieros en el año 2011 fueron muy positivos debido, principalmente, al buen momento del precio del oro.
Para Apostolides (2007) una asamblea con buenas prácticas de gobierno corporativo es aquella en la que el accionista minoritario está bien atendido, su voz es escuchada y sus propuestas consideradas por la junta directiva. En la asamblea de Mineros S.A. los accionistas minoritarios tuvieron un papel activo y el trato de la junta directiva hacia ellos fue cordial. Uno de los episodios más importantes durante la asamblea fue la votación de la propuesta de los dividendos a distribuir; debido a que uno de los accionistas minoritarios presentó otra propuesta a la junta y la sometió a consideración, esta propuesta fue discutida por el accionista mayoritario y aprobada por la presidencia de la empresa.

Adicionalmente la asamblea fue sobria y muy concurrida, considerando el espacio en el que se celebró. La mayoría de los criterios de evaluación según Apostolides (2007) se cumplieron, exceptuando el criterio de la 
composición de la junta y el tema de los apoderados con calificación de cero cada uno; en el primer caso se presenta que en la junta la planilla principal está conformada por hombres, no hay presencia de mujeres ni de extranjeros ${ }^{2}$, y adicionalmente en la mesa principal de la asamblea no estaban visibles los siete miembros que conforman la junta. En cuanto al tema de los apoderados, no se evidencia favorecimiento de los accionistas minoritarios ni de la gerencia.

Las empresas pertenecientes al Grupo Empresarial Antioqueño, (Grupo Bancolombia, Celsia, Grupo Nutresa, Protección, Grupo Sura, Grupo éxito, Enka) obtuvieron entre el $66,67 \%$ y el $50 \%$ de la calificación porcentual en el desempeño de su asamblea, exceptuando a la compañía de pensiones y cesantías Protección S.A. de la cual se hablará más adelante. De este conjunto de empresas se rescata el buen trato del presidente hacia los accionistas en las asambleas del Grupo Nutresa y Grupo Bancolombia; el sistema de votación del Grupo Éxito, que utilizó urnas para elegir las nuevas planillas de la junta directiva. La asamblea de Enka fue muy sobria y poco concurrida, y a pesar que el quórum fue del $54,44 \%$, se destaca la

La presencia de mujeres en las juntas es deseada para garantizar diversidad de género en estos órganos de gobierno y, porque de acuerdo con investigaciones previas imponen disciplina a las reuniones, son eficientes en los comités de auditoría, y menos propensas a la corrupción, entre otros aspectos. Los directores extranjeros regularmente representan los intereses de inversionistas radicados en otros países, y en otras ocasiones pueden ejercer como directores independientes con altos niveles de conocimiento sobre mercados internacionales en los que las empresas locales desean incursionar o ganar posicionamiento. buena atención a los asistentes al evento y el responder con prontitud las inquietudes. Las Asambleas de Celsia y Grupo Sura fueron de las más asistidas y formales. En el caso de la empresa Celsia no hubo intervención por parte de accionistas minoritarios, y en la asamblea de Sura se rescata la confianza de los accionistas hacia esta empresa debido al buen momento que estaban atravesando dadas nuevas inversiones en otros países.

En general las Asambleas duraron en promedio dos horas, a excepción de las asambleas de ISA e Isagen las cuales tuvieron una duración de más de cuatro horas. Lo anterior puede ser consistente con la idea que las empresas de propiedad del Estado están sujetas a mayor supervisión y escrutinio. Lo anterior se sustenta por un lado porque la junta directiva presenta a los accionistas su gestión de manera detallada, lo que no ocurre en el resto de asambleas y adicionalmente los accionistas tienen un espacio importante para intervenir. La asamblea de Isagen transcurrió con mucha calma y normalidad aunque algunos accionistas minoritarios propusieron que alguno de ellos fuera quien los representara en la junta directiva, pero destacaron que los actuales directores han hecho un buen trabajo. En la asamblea de ISA algunos accionistas minoritarios manifestaron no identificarse con la junta directiva, hubo mucha intervención y por momentos se evidenció falta de control en la asamblea por parte de la dirección.

Según los criterios de Apostolides, las asambleas con calificación más baja son Protección y Edatel. La celebración de la AGA de Protección se sale del esquema del resto de 
las asambleas analizadas, se realizó en una sala de juntas en el edificio donde quedan las oficinas de la compañía, asistió la junta directiva, la revisoría fiscal y la secretaría general; el quórum fue del 91,54\% de acciones representadas. Los accionistas minoritarios asisten a la asamblea por medio de representación lo cual es válido por ley; pero bajo el fundamento planteado en la investigación sobre la importancia de un encuentro directo entre accionistas minoritarios y directivos, la comunicación entre ellos y la rendición de cuentas por parte de los últimos no encaja dentro de los postulados de la literatura revisada.

En el caso de Edatel el quórum de la asamblea fue del 79,77\%. Hubo abstención de voto por parte de tres representantes de los fondos de pensiones, al no tener garantía de la independencia de los postulados a nuevos miembros de la junta directiva respecto a la afiliación a los fondos de pensiones (Decreto 2955, 2010); esta situación deja una mala impresión de la compañía frente a las prácticas de buen gobierno corporativo que sugieren que los accionistas deben conocer las hojas de vida de quienes se postulan a hacer parte de la junta directiva con suficiente tiempo, para poder participar activamente en la asamblea. Además, por momentos la asamblea se salió del control de la dirección, hubo desorden y en la mesa principal no estuvieron los siete miembros de la junta directiva. En general, la celebración de esta asamblea pasa por alto algunos criterios de buenas prácticas corporativas.

Lo anterior sustenta que las asambleas son medios que las empresas utilizan para dar a conocer su gestión a aquellos accionistas que no tienen comunicación directa con la dirección de la empresa, y los accionistas minoritarios esperan la convocatoria para participar en la asamblea con el fin de permitirles a algunos conocer más de la empresa en la que han invertido su dinero, y en lo posible, dar su opinión. Para otros accionistas la asamblea es una reunión en la que obtienen obsequios y les permite pasar un rato agradable, además de sentirse parte de la empresa y conocer de cerca a quienes dirigen la compañía. Según este análisis las empresas emisoras de valores más representativas de Colombia tienen un nivel intermedio de buenas prácticas de gobierno corporativo en el desarrollo de sus AGA.

Para analizar las fortalezas y las debilidades relacionadas, se propone la construcción de un índice agregado compuesto por cada criterio evaluado, de tal manera que si la muestra es de once empresas, dado que la puntuación de cada criterio es de $1,0 \mathrm{y}-1$, el puntaje máximo será de 11 y el mínimo de -11. Lo anterior permite determinar cuáles de los criterios propuestos por Apostolides se aplican con mayor frecuencia a favor de los accionistas minoritarios y cuáles no.

El panel B del cuadro 3 muestra que los criterios con mayor valoración son la agenda, informe de la dirección, los refrigerios y los materiales con un valor de 11 puntos cada uno, es decir que todas las asambleas de la muestra aplican este criterio a favor del accionista minoritario. El segundo criterio con mayor puntuación es la sede con siete puntos (sólo las asambleas de Edatel y Protección no escogen una sede para organizar 


\section{Cuadro 3. Evaluación utilizando la metodología de Apostolides}

Panel A: Este panel muestra la posición de las AGA según la evaluación realizada a cada asamblea teniendo en cuenta los doce elementos considerados en la metodología de Apostolides. Un puntaje de $100 \%$ es posible solo si la empresa obtiene 12 puntos de los 12 posibles.

\begin{tabular}{|l|c|c|}
\hline \multicolumn{1}{|c|}{ Empresa } & Puntaje Asamblea (\%) & Posición \\
\hline Mineros S.A. & 83,33 & 1 \\
\hline Almacenes Éxito S.A. & 66,67 & 2 \\
\hline Isagen S.A. E.S.P. & 66,67 & 2 \\
\hline Grupo Bancolombia S.A. & 58,33 & 3 \\
\hline Grupo Nutresa S.A & 58,33 & 3 \\
\hline Grupo de Inversiones Suramericana S.A. & 50,00 & 4 \\
\hline Colinversiones (CELSIA) & 50,00 & 4 \\
\hline Enka de Colombia S.A. & 50,00 & 4 \\
\hline Interconexión Eléctrica S.A. E.S.P. (ISA) & 41,67 & 5 \\
\hline Edatel S.A. E.S.P. & 33,33 & 6 \\
\hline Protección S.A. & 33,33 & 6 \\
\hline
\end{tabular}

Fuente: elaboración propia.

la AGA en la que el accionista minoritario se encuentre a gusto). Retribución económica de la junta directiva, las preguntas realizadas y el control que ejercen los directivos en la Asamblea obtienen solo cuatro puntos de 11 posibles. Al respecto, solo cuatro empresas demuestran tener juntas directivas conformadas con directores de experiencia sin asumir costos excesivos; la empresa Edatel obtuvo puntuación negativa porque no hubo mucho control en la Asamblea; y Protección obtiene puntuación negativa porque en su Asamblea no hubo intervención de accionistas.

La composición de la junta directiva solo tuvo puntos positivos en las asambleas del Éxito, Protección, Isagen y Celsia porque tienen dentro de sus miembros a mujeres, y en el caso de almacenes Éxito asisten extranjeros. En cuanto al procedimiento de votación, sólo dos empresas se destacaron por innovar. En el caso del grupo Éxito, y Mineros S.A. el accionista mayoritario accedió a la petición de un accionista minoritario. El criterio que no tuvo ninguna puntuación fue el de los apoderados ya que en las asambleas no fue posible observar si los apoderados pudieron intervenir. Solo cinco criterios de doce fueron realizados con más frecuencia en las asambleas a favor de los accionistas. Además, se debe tener en cuenta que criterios trascendentales para el accionista minoritario como el balance y la remuneración de la junta, el espacio para preguntas y los procedimientos de voto obtuvieron calificaciones inferiores al $50 \%$ del total de puntos posibles en la muestra. Lo anterior señala en Colombia un nivel 


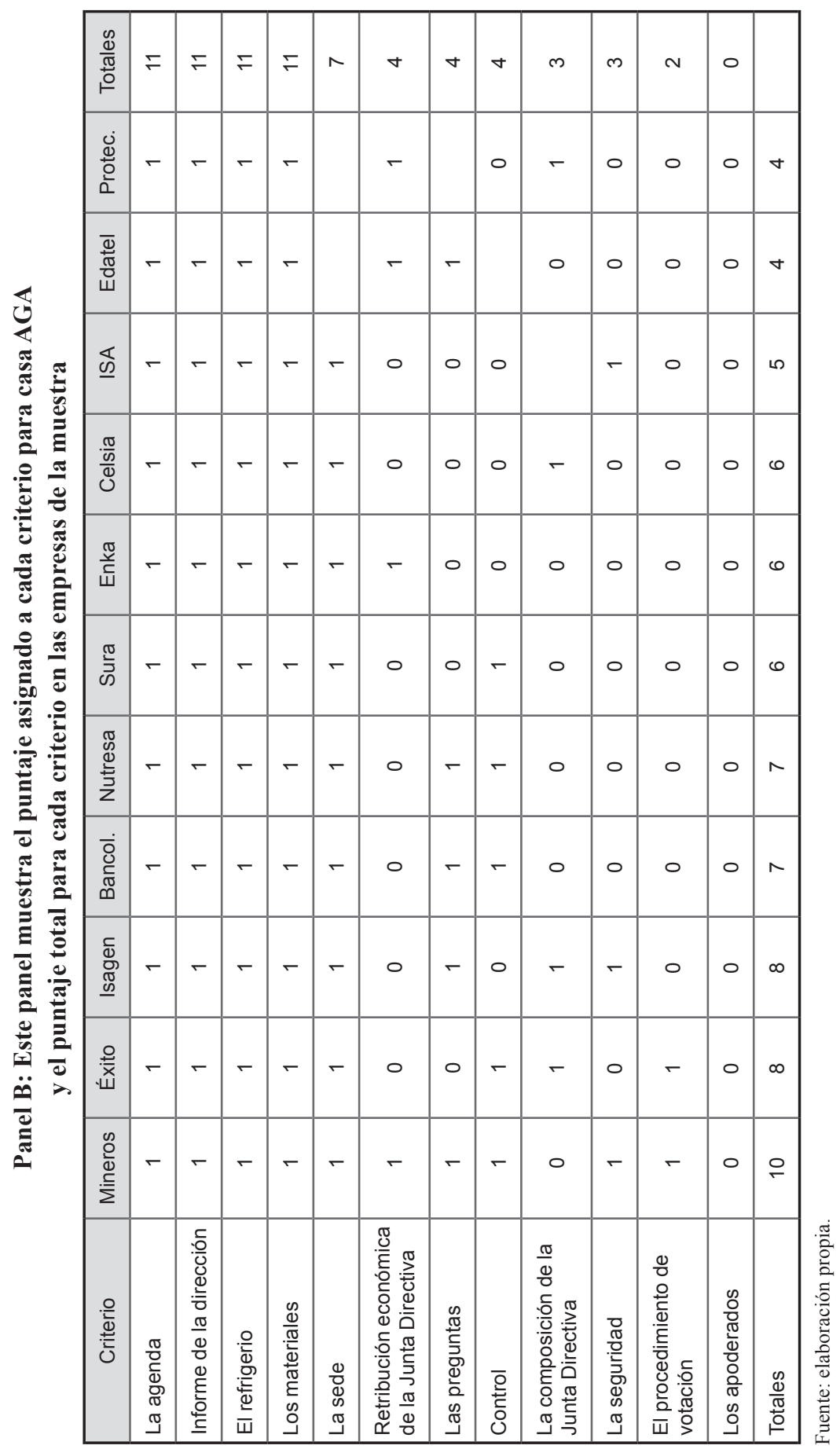


medio-bajo de desempeño en relación con buenas prácticas de gobierno corporativo.

Apostolides (2007) realizó un estudio para el periodo 2001-2005 de las AGA en Reino Unido utilizando una muestra de 22 empresas que pertenecen a sectores como el bancario, comercio al por menor, deportivo, petrolero, farmacéutico, entre otros. Se realizó una evaluación de las asambleas de acuerdo con los doce criterios que propone este autor. Los resultados del estudio muestran que sólo cinco compañías de las 22 que componen la muestra obtuvieron puntuación igual o superior al $50 \%$ de los criterios evaluados, mientras que 17 de ellas presentan resultados inferiores. Es decir, tan sólo el 23\% de las empresas de la muestra evidencian una buena rendición de cuentas a sus accionistas, mientras que más del $73 \%$ de las mismas no desarrollan asambleas generales que respondan a buenas prácticas de gobierno corporativo.

Lo anterior muestra que, similar a los hallazgos que presentamos para Colombia, Apostolides (2007) encuentra un nivel mediobajo de desempeño en relación con buenas prácticas de gobierno corporativo en las asambleas evaluadas en el estudio. Por otra parte, en el estudio realizado por Apostolides (2007) el sector bancario y el de comercio al por menor son los mejores evaluados mientras que el sector deportivo obtiene la evaluación más baja. De igual manera, los sectores con mejores prácticas de gobierno corporativo en las AGA evaluadas en Colombia son el financiero y el de comercio al por menor, representado por Bancolombia y el Grupo Éxito respectivamente. En general, de acuerdo con los criterios propuestos por Apostolides (2007), tanto en Colombia como en el Reino Unido menos de la mitad de las empresas cuenta con un buen nivel de rendición de cuentas en las AGA.

La similitud en los resultados resalta aún más la importancia de la implementación de mejores prácticas a nivel de empresa para el caso colombiano. Estudios previos, como los de La Porta et al. $(1997,1998)$ y La Porta et al. (1999) muestran para el caso del Reino Unido un buen nivel de protección legal a los inversionistas, una alta dispersión de la propiedad, un mayor nivel de capitalización de las empresas listadas en el mercado en términos absolutos y relativos respecto al PIB, y en general, un mayor desarrollo del mercado de capitales. Como se discutió previamente, las prácticas a nivel de empresa cobran mayor importancia cuando el país no ofrece un marco regulatorio fuerte que proteja a los inversionistas. Debido a que Colombia siempre obtiene puntajes inferiores respecto a la protección legal ofrecida a los inversionistas y el desarrollo de su mercado de capitales en comparación con Reino Unido, fortalecer las prácticas a nivel de empresa en las AGA es aún más necesario para las empresas colombianas, buscando mitigar conflictos de intereses entre accionistas mayoritarios y minoritarios, mejorar la reputación de las empresas y obtener con mayor facilidad fondos para financiar sus actividades.

Todas las empresas colombianas en la muestra utilizada en este estudio cuentan con accionistas controlantes. El promedio de participación de los mayoritarios de estas empresas para el año 2012 es de 42,82\%. 
De las once empresas, tres son controladas por el Estado y las restantes son controladas por otras empresas domésticas, la mayoría de ellas con afiliación a algún grupo económico. Además, se evidencia la participación de inversionistas institucionales, como los fondos de pensiones, en la mayoría de ellas. Sin embargo, el control que pueden realizar estos inversionistas a los accionistas mayoritarios está limitado por sus participaciones minoritarias. Esta concentración de la propiedad crea un escenario en el que el mayoritario puede utilizar su poder para influenciar las decisiones de la empresa, lo cual puede beneficiar o perjudicar a los minoritarios. Por ello, las buenas prácticas a nivel de las AGA son necesarias para garantizar que estas reuniones funcionen como un escenario de resolución de conflictos, rendición de cuentas y participación de los accionistas minoritarios en el gobierno de la empresa. Sin embargo, ante regulación silenciosa y auto regulación incipiente, las AGA pueden convertirse en un trámite a cumplir en lugar de una oportunidad para involucrar a los demás accionistas y rendir cuentas.

\subsection{Código País y las $A G A$ en Colombia}

El cuadro 4 recoge la información del cumplimiento de las empresas colombianas de la muestra según lo reportado en la encuesta de mejores prácticas de buen gobierno corporativo realizada en el país (Encuesta Código País). La puntuación asignada a cada empresa se encuentra detallada y está disponible bajo solicitud. Como se explicó anteriormente, las empresas que en cada pregunta respondieron si se calificaron con un valor de 1, las que respondieron no con un valor de -1 y las respuestas n.a. (no aplica) obtuvieron valor nulo. Es necesario señalar que las encuestas muestran algunas inconsistencias entre la marcación de no como respuesta y los comentarios que justifican las respuestas negativas. En algunas ocasiones, al analizar los comentarios se evidencia que realmente la respuesta debía ser afirmativa o que no aplicaba, por lo que se otorgó la calificación teniendo en cuenta los comentarios ${ }^{3}$.

El panel A en el cuadro 4 muestra el porcentaje de cumplimiento de las medidas o recomendaciones realizadas por el Código País relacionadas con las AGA para cada firma. Este porcentaje resulta de dividir el total de puntos obtenidos por la empresa sobre el total de puntos posibles. El total de puntos posibles puede ser de 20 o menos, al no tener en cuenta las preguntas que no aplican para cada empresa. Los resultados obtenidos muestran que Isa, Isagen y Grupo Nutresa cumplen en un $100 \%$ las medidas del Código relacionadas con las AGA para el periodo 2007-2011 (con respecto al total de preguntas que si aplica para cada empresa). Estas empresas sobresalen con respecto a las demás porque cumplen en todos los años con las sugerencias asociadas a las preguntas Q2 y Q12, relacionadas con la revelación de información de los candidatos a conformar

Evidencia de lo anterior se encuentra en las respuestas a las preguntas 18,19 y 20 relacionadas con el hecho de tener un reglamento interno del funcionamiento de las asambleas. Algunas empresas contestaban no y en los comentarios afirmaban que sí tenían dicho reglamento pero incluido en los estatutos, o en su código de gobierno. 
la junta directiva al momento de realizar la convocatoria y con la transmisión vía web de la asamblea para aquellos accionistas que no puedan asistir a la misma.

Las empresas con la calificación más baja fueron Mineros y Edatel. Entre los factores que afectan la calificación de estas empresas están el no contar con medios electrónicos para que los accionistas puedan ver el desarrollo de la AGA a través de las páginas web o Internet, no contar con un reglamento interno para el funcionamiento de las AGA y no proporcionar información previa a la asamblea relacionada con el perfil de los candidatos a conformar la junta directiva.

El panel B en el cuadro 4 muestra la puntuación total agregada obtenida por cada una de las 20 preguntas relacionadas con las AGA, de acuerdo con las respuestas de cada empresa incluida en la muestra y el puntaje asignado por los autores a estas respuestas. Los resultados siguiendo este sistema de evaluación muestran que, previamente a las AGA, todas las empresas de la muestra ponen a disposición de los accionistas información sobre los temas a tratar, presentan un orden del día desagregado e informan la clase y cantidad de acciones emitidas. El bajo puntaje en algunas preguntas obedece a que la mayoría de empresas respondieron no aplica, y son las relacionadas con operaciones especiales (Q6, Q7 y Q13), cambio de objeto social (Q8), renuncia a derechos especiales (Q9), cambio de domicilio (Q10), y disolución anticipada (Q11). En general, se observa incumplimiento de las empresas durante el periodo 2008-2011 en las recomendaciones relacionadas con preguntas Q2 y Q12, por lo que las empresas que deseen mejorar en las prácticas de gobierno relacionadas con las AGA deben proporcionar de forma oportuna a los accionistas información relacionada con el perfil de los candidatos a conformar la junta directiva y transmitir por medios electrónicos la AGA a quienes no puedan asistir.

Se concluye que las empresas de la muestra en los últimos años han dado cumplimiento en su mayoría a las medidas del código. Sin embargo, es posible mejorar en aspectos cruciales relacionado con la divulgación de los perfiles de los candidatos a conformar la junta directiva y en hacer más fácil la asistencia a las AGA, a través del uso de Internet.

El cuadro 5 resume los resultados de cada una de las evaluaciones sobre el desempeño de las asambleas de la muestra, teniendo en cuenta los criterios de Apostolides y las recomendaciones propuestas en el Código País a través de la Encuesta Código País. Es necesario discutir la diferencia en los resultados de las dos metodologías, ya que siguiendo a Apostolides el mejor puntaje lo obtiene Mineros S.A., empresa con el puntaje más bajo al tener en cuenta las recomendaciones del Código País. Al revisar los aspectos ponderados en cada medición se encuentra que son complementarios. Apostolides valora aspectos fundamentales como los procedimientos mediante los cuales se ejerce el voto, el espacio para preguntas de los accionistas minoritarios a la alta dirección, la composición de la junta y el reporte de remuneración de la misma, los cuales no son tenidos en cuenta en la valoración que se realiza siguiendo las recomendaciones del 
Cuadro 4. Evaluación utilizando la Encuesta sobre el Código País

Panel A: Este panel muestra el cumplimiento histórico de las recomendaciones incluidas en el Código colombiano de mejores prácticas (Código País) de acuerdo con las respuestas provistas por cada empresa en el periodo 2008-2011 a través de la Encuesta del Código País realizada por la Superintendencia Financiera (SFIN)

\begin{tabular}{|l|c|c|c|c|c|c|}
\hline \multicolumn{1}{|c|}{ Empresas } & $2008(\%)$ & $2009(\%)$ & $2010(\%)$ & $2011(\%)$ & $\begin{array}{c}\text { Promedio } \\
(\%)\end{array}$ & Posición \\
\hline Interconexión Eléctrica S.A. E.S.P. (ISA) & 100 & 100 & 100 & 100 & 100 & 1 \\
\hline Isagen S.A. E.S.P. & 100 & 100 & 100 & 100 & 100 & 1 \\
\hline Grupo Nutresa S.A & 100 & 100 & 100 & 100 & 100 & 1 \\
\hline Colinversiones (CELSIA) & 85 & 100 & 100 & 100 & 96 & 2 \\
\hline Grupo Bancolombia S.A. & 100 & 85 & 100 & 100 & 96 & 2 \\
\hline Grupo de Inversiones Suramericana S.A. & 100 & 100 & 85 & 85 & 93 & 3 \\
\hline Protección S.A. & 100 & 83 & 100 & 83 & 92 & 4 \\
\hline Almacenes Éxito S.A. & 67 & 67 & 100 & 100 & 84 & 5 \\
\hline Enka de Colombia S.A. & 67 & 82 & 67 & 82 & 75 & 6 \\
\hline Edatel S.A. E.S.P. & 69 & 69 & 69 & 69 & 69 & 7 \\
\hline Mineros S.A. & 38 & 45 & 45 & 69 & 49 & 8 \\
\hline
\end{tabular}

Fuente: elaboración propia.

Panel B: Este panel muestra el puntaje total que se obtuvo para cada una de las preguntas de la Encuesta Código País de acuerdo con las respuestas provistas por cada empresa en la muestra

\begin{tabular}{|l|c|c|c|c|c|c|}
\hline Pregunta & 2008 & 2009 & 2010 & 2011 & Promedio & Posición \\
\hline P 1 & 11 & 11 & 11 & 11 & 11,00 & 1 \\
\hline P 5 & 11 & 11 & 11 & 11 & 11,00 & 1 \\
\hline P 15 & 11 & 11 & 11 & 11 & 11,00 & 1 \\
\hline P 16 & 11 & 11 & 11 & 11 & 11,00 & 1 \\
\hline P 17 & 11 & 9 & 11 & 11 & 10,25 & 2 \\
\hline P 14 & 9 & 10 & 11 & 11 & 10,00 & 3 \\
\hline P 4 & 9 & 9 & 10 & 11 & 9,75 & 4 \\
\hline P 18 & 9 & 9 & 10 & 11 & 9,75 & 5 \\
\hline P 19 & 9 & 10 & 11 & 9,75 & 5 \\
\hline P 20 & 9 & 9 & & 5 \\
\hline
\end{tabular}




\begin{tabular}{|l|c|c|c|c|c|c|}
\hline Pregunta & 2008 & 2009 & 2010 & 2011 & Promedio & Posición \\
\hline P 3 & 6 & 6 & 6 & 6 & 6,00 & 6 \\
\hline P 12 & 3 & 6 & 5 & 5 & 4,75 & 7 \\
\hline P 2 & 7 & 3 & 4 & 4 & 4,50 & 8 \\
\hline P 13 & 2 & 2 & 1 & 1 & 1,50 & 9 \\
\hline P 9 & 0 & 1 & 0 & 0 & 0,50 & 10 \\
\hline P 6 & 1 & 2 & 0 & 0 & 0,25 & 10 \\
\hline P 8 & 0 & 0 & 0 & 0 & 0,00 & 12 \\
\hline P 7 & 0 & 0 & 0 & 0 & 0,00 & 12 \\
\hline P 10 & 0 & 0 & 0 & 0 & 0,00 & 12 \\
\hline P 11 & & 1 & & 0 & 12 \\
\hline
\end{tabular}

Fuente: elaboración propia.

Código País. Sin embargo, el Código País incluye recomendaciones que no se tienen en cuenta bajo la metodología de Apostolides, como la revelación anticipada de los perfiles de los candidatos a ocupar puestos en la junta directiva, la existencia de un reglamento para el desarrollo de las AGA, la posibilidad de atender la asamblea de manera virtual, y la inclusión en el orden del día y aprobación de operaciones que pueden afectar la riqueza de los minoritarios durante el desarrollo de la asamblea.

\section{Recomendaciones para buenas prácticas de gobierno corporativo en las AGA}

Los mercados de capitales en Latinoamérica se caracterizan por un alto costo de capital, poca profundidad, bajo número de emisores $\mathrm{y}$ un marco regulatorio en desarrollo (Lefort 2005; Klappler y Love 2004; Chong y López de Silanes 2007). Colombia, Chile y Perú han creado un mercado de renta variable integrado, denominado MILA: Mercado Integrado Latinoamericano, buscando mayor diversificación, mayor democratización accionaria, mejor balance riesgo-retorno, disminución en los costos de capital y una mayor internacionalización de los mercados latinos y de sus marcos legales. El MILA inició operaciones el 30 de mayo de 2011, convirtiéndose en el primer mercado de capitales de la región en número de emisores (en mayo de 2012 contaba con 548 empresas: 236 peruanas, 228 chilenas y 84 colombianas). Lo anterior señala la urgencia de trabajar en unos mínimos de gobierno corporativo para el desarrollo de las AGA que velen por los intereses de los accionistas minoritarios y que sean adoptados por los países de la región, por otros países emergentes con marcos regulatorios en desarrollo e incluso, por países desarrollados que tengan la posibilidad de mejorar y convertir las AGA en mecanismos efectivos de gobierno corporativo. 
Cuadro 5. Puntajes obtenidos por las AGA siguiendo los lineamientos de Apostolides y el Código País

\begin{tabular}{|l|c|c|c|c|}
\hline \multicolumn{1}{|c|}{ Empresa } & $\begin{array}{c}\text { Puntaje } \\
\text { Apostolides (\%) }\end{array}$ & $\begin{array}{c}\text { Puntaje } \\
\text { Código País (\%) }\end{array}$ & Promedio (\%) & Posición \\
\hline Isagen S.A. E.S.P. & 66,67 & 100,00 & 83,33 & 1 \\
\hline Grupo Nutresa S.A & 58,33 & 100,00 & 79,17 & 2 \\
\hline Grupo Bancolombia S.A. & 58,33 & 96,25 & 77,29 & 3 \\
\hline Almacenes Éxito S.A. & 66,67 & 83,50 & 75,08 & 4 \\
\hline Colinversiones (CELSIA) & 50,00 & 96,25 & 73,13 & 6 \\
\hline Grupo de Inversiones & 50,00 & 92,50 & 71,25 & 7 \\
\hline Suramericana S.A. & 41,67 & 100,00 & 70,83 & 8 \\
\hline Interconexión Eléctrica S.A. E.S.P. (ISA) & 83,33 & 49,25 & 66,29 & 9 \\
\hline Mineros S.A. & 33,33 & 91,50 & 62,42 & 11 \\
\hline Protección S.A. & 50,00 & 74,50 & 62,25 & 51,17 \\
\hline Enka de Colombia S.A. & 33,33 & 69,00 & & 7 \\
\hline Edatel S.A. E.S.P. & & & & 7 \\
\hline
\end{tabular}

Fuente: elaboración propia.

La evaluación realizada a las AGA en Colombia permite identificar aspectos fundamentales para la satisfacción del accionista minoritario en estas reuniones y para el buen gobierno de la empresa que ya se aplican con regularidad, como por ejemplo, el establecimiento de reglamentos para las AGA incluyendo detalles sobre la convocatoria y la reunión, el diseño y seguimiento a una agenda detallada para la reunión, el envío de materiales previo a la misma, el informe de la alta dirección, y esfuerzos por la satisfacción del accionista durante la AGA a través de la escogencia de una buena sede y de la entrega de refrigerios.

Sin embargo, se identifican igualmente aspectos que permitirían mejoras de fondo respecto a las AGA como instrumentos de buen gobierno. La asistencia a las asambleas de las empresas de la muestra permitió identificar algunos accionistas minoritarios que no se sentían representados por la junta directiva, y asambleas para las cuales no se entregó con suficiente tiempo a los accionistas las hojas de vida de los postulantes a miembros de junta directiva. Por lo tanto, se recomienda establecer mecanismos para que en la planilla de postulantes a miembros de junta directiva se incluyan candidatos propuestos por accionistas minoritarios y que las hojas de vida de todos los candidatos sean conocidas por los accionistas con suficiente antelación a la fecha de la celebración de la asamblea.

Los principios de buen gobierno en general sugieren el tratamiento equitativo de los accionistas buscando la participación de los accionistas minoritarios en la toma de decisiones de la empresa y procurando una 
relación equitativa entre los derechos a voto y los derechos sobre flujos de caja. Por lo tanto, se recomienda que la sociedad emisora de acciones sin derecho a voto, ofrezca a sus tenedores la oportunidad de canjearlos por acciones ordinarias con derecho a voto y que anticipen esta posibilidad al momento de su emisión.

Strätling (2003) y los principios de gobierno corporativo de la OCDE (2004) sugieren a las empresas incorporar en las asambleas instrumentos que faciliten tanto a accionistas extranjeros como aquellos que no puedan asistir a las asambleas la posibilidad de votar en tiempo real. Por lo anterior, se recomienda que en el proceso de votación se permita el uso de medios electrónicos, que garanticen transparencia y facilite el voto para quienes no puedan asistir de manera presencial a la AGA.

La literatura reseñada previamente-De Jong, Merten y Roosenboom (2006), Iwatani y Taki (2009) y Poulsen, Strand y Thomsen (2010)-destaca que el papel que ejercen los fondos de pensiones como inversionistas institucionales es valorado cada vez más por sus cotizantes, ya que se espera un papel de supervisión como accionistas representativos. Teniendo en cuenta estos planteamientos, se sugiere que, con el objetivo de promover la transparencia, los inversionistas institucionales que actúan en calidad de fiduciarios (como los fondos de pensiones) revelen su intención de voto (OCDE, 2004).

El trabajo de campo aquí realizado pone de manifiesto la importancia de innovar en los procesos de votación. Por ejemplo, pa- ra promover la trasparencia se puede dejar constancia de la votación de cada accionista, situación que no es evidente cuando las propuestas son votadas por aclamación. Por lo tanto, se sugiere que toda votación que se efectúe en una asamblea se realice mediante un sistema que asegure la simultaneidad en el ejercicio del voto y un proceso público de escrutinio que permita conocer la decisión de cada accionista. Además, se sugiere a las empresas implementar mecanismos de voto que permitan a los accionistas minoritarios participar activamente de las decisiones que se someten a aprobación, lo que implica no ponderar el voto por la participación de los accionistas sobre la propiedad de la empresa.

Adicional a las recomendaciones anteriores se recomienda a las empresas trabajar en la estructuración de juntas directivas que incluyan diversidad de perfiles profesionales, género $y$, si se considera necesario, nacionalidad, para que los accionistas minoritarios perciban fortalezas en el directorio, como una variedad de puntos de vista que enriquezca las discusiones llevadas a cabo. Además, se debe trabajar en una rendición clara sobre la remuneración de los directores de las empresas, buscando modificar la percepción de los accionistas en cuanto a la relación costo beneficio de estos órganos de gobierno.

El bajo nivel de activismo de los accionistas minoritarios percibido en las AGA invita a pensar que la implementación de estas sugerencias, junto con campañas por un cambio cultural al respecto, haría de las asambleas espacios en el que verdaderamente se ejerzan los derechos de los accionistas. 


\section{Comentario final}

El buen gobierno corporativo facilita la movilidad de capital de un país a otro, porque proporciona a las empresas credibilidad y transparencia en su relación con los inversionistas. Lo anterior ha sido reconocido por organismos multilaterales y reguladores en mercados emergentes, quienes han liderado estrategias que buscan la implementación de prácticas de buen gobierno corporativo en las empresas, tanto listadas como cerradas y familiares.

Aun cuando se han presentado avances a nivel país y a nivel firma, este estudio señala el nivel medio-bajo en el que se encuentra las AGA en Colombia como instrumentos de Gobierno Corporativo. Luego de hacer una evaluación siguiendo los criterios de los trabajos de Apostolides $(2007,2010)$ y los lineamientos del Código País, se encontró que con los criterios de Apostolides, la percepción sobre la composición de la junta directiva y el informe de remuneración de la misma, el espacio para preguntas por parte de los accionistas minoritarios y el procedimiento de votación son los criterios con menor puntuación. Además, revisando el cumplimiento a las recomendaciones presentadas por el Código País, se encuentra que no se presenta previamente al desarrollo de la AGA la información que los accionistas deben tener sobre el perfil de los candidatos a junta directiva, $y$ no se permite el ejercicio del voto y la asistencia a la reunión a través de medios electrónicos.

Teniendo en cuenta los resultados encontrados se presentan recomendaciones puntuales que pueden ser implementadas por las empresas que desean mejorar sus prácticas de gobierno corporativo o que pueden ser incorporadas en los códigos de buen gobierno que buscan incentivar una cultura de autorregulación o en los marcos legales de países que buscan fortalecer sus sistemas de gobierno corporativo desde una convergencia legal.

Finalmente, sugerimos trabajar en un cambio cultural para que el accionista minoritario sea más activo en las AGA y valore estos escenarios como instrumentos válidos de gobierno corporativo. Las asambleas son reconocidas en la literatura y en los códigos de buen gobierno promulgados por organismos multilaterales y países como escenarios de ejercicio de los derechos de los accionistas, especialmente los minoritarios. Sin embargo, lo anterior parece no ser asumido como tal por estos últimos, quienes presentan un bajo nivel de activismo en las AGA.

\section{Referencias}

Apostolides, N., and Boden, R. (2005). Cedric the Pig: Annual General Meetings and Corporate Governance in the UK. Social Responsibility Journal, 1 (1), 53-62.

Apostolides, N. (2007). Directors versus shareholders: Evaluating corporate governance in the UK using the AGM scorecard. Corporate Governance: An International Review, 15 (6), 1227-1287.

Apostolides, N. (2010). Exercising corporate governance at the annual general meeting. Corporate Governance. The International Journal of Business in Society, 10 (2),140-149.

Chong, A., and López de Silanes, F. (2007). Corporate Governance in Latin America. In A. 
Chong and F. Lopez-de-Silanes (Eds.), Investor protection and corporate governance: Firmlevel evidence across Latin America. Stanford: Stanford University Press.

De Jong, A., Mertens, G., and Roosenboom, P. (2006). Shareholders' voting at general meetings: Evidence from the Netherlands. Journal of Management \& Governance, 10 (4), 353-380.

Dimitrov, V., and Jain, P. (2011). It's showtime: Do managers report better news before annual shareholder meetings? Journal of Accounting Research, 49 (5), 1193-1221.

Fairfax, L. (2010). Virtual Shareholder Meetings Reconsidered. Seton Hall Law Review, 40 (4), 1367-1431.

Hodges, R., Macniven, L. and Mellett, H. (2004). Governance of UK NHS Trusts: The Annual General Meeting. Corporate Governance: An International Review, 12 (3), 343-352.

Iwatani, M., and Taki, T. (2009). Evolution of General Shareholders' Meetings in Japan. Nomura Journal of Capital Markets, 1 (1), 1-17.

Jensen, M., and Meckling, W. (1976). Theory of the firm: Managerial behavior, agency costs and ownership structure. Journal of Financial Economics, 3 (4), 305-360.

Klapper, L., and Love, I. (2004). Corporate governance, investor protection, and performance in emerging markets. Journal of Corporate Finance, 10 (5), 703-728.

La Porta, R., Lopez-De-Silanes, F., and Shleifer, A. (1999). Corporate Ownership around the World. The Journal of Finance, 54 (2), 471-517.

La Porta, R., Lopez-De-Silanes, F., Shleifer, A., and Vishny, R. W. (1997). Legal determinants of external finance. The Journal of Finance, 52 (3), 1131-1150.

La Porta, R., Lopez-De-Silanes, F., Shleifer, A., and Vishny, R. W. (1998). Law and Finance.
The Journal of Political Economy, 106 (6), 1113-1155.

Lefort, F. (2005). Ownership structure and corporate governance in Latin America. ABANTE, 8 (1), 55-84.

OCDE (2004). Principios de Gobierno Corporativo de la OCDE. Paris.

Poulsen, T., Strand, T., and Thomsen, S. (2010). Voting power and shareholder activism: A study of Swedish shareholder meetings. Corporate Governance: An International Review, 18 (4), 329-343.

Shleifer, A., and Vishny, R. W. (1986). Large shareholders and corporate control. The Journal of Political Economy, 94 (3), 461-488.

Sjostrom, W. (2007). The case against mandatory annual director elections and shareholders' meetings. Tennessee Law Review, 74 (2), 199-239.

Strätling, R. (2003). General meetings: A dispensable tool for corporate governance of listed companies? Corporate Governance: An International Review, 11 (1), 74-82.

Superintendencia Financiera de Colombia (2010). Documento Conceptual de Gobierno Corporativo. Delegatura para riesgos de conglomerados y gobierno corporativo. Subdirección de metodologías de supervisión y análisis de riesgos. Bogotá, Colombia.

Tirole, J. (2001). Corporate Governance. Econometrica, 69 (1), 1-35.

Zetzsche, D. (2005). Shareholder interaction preceding shareholder meetings of public corporations - a six country comparison. Available at SSRN: http://dx.doi.org/10.2139/ssrn.624241. Zetzsche, D. (2007). Virtual Shareholder Meetings and the European Shareholder Rights Directive - Challenges and Opportunities. Available at SSRN: http://dx.doi.org/10.2139/ssrn.996434. 